\title{
Olhares etnográficos para uma torcida organizada de futebol: Os Gaviões da Fiel
}

Resenha: HOLLANDA, Bernardo B.; NEGREIROS, Plínio L. (Org.). Os Gaviões da Fiel Ensaios e Etnografias de uma torcida organizada de futebol. Rio de Janeiro: Editora 7 Letras, 2015.

Marianna Castellano Barcelos de Andrade ${ }^{1}$

Publicado no ano de 2015 com organização dos historiadores Bernardo Buarque de Hollanda e Plínio Labriola Negreiros, o livro "Os Gaviões da Fiel - Ensaios e Etnografias de uma torcida organizada de futebol" traz um compilado de textos etnográficos e ensaios escrito por diversos pesquisadores estudiosos do futebol, sobre a primeira e maior agremiação torcedora do Estado de São Paulo, o Grêmio Gaviões da Fiel. O objetivo desta resenha, mais do que uma apresentação detalhada do livro, é discutir como a etnografia é mobilizada em alguns dos textos de sua segunda parte, nomeadamente mais etnográfica. Uma vez que a etnografia é marcada por uma série de controvérsias no campo da antropologia, em que muitos autores a veem apenas como um método ou um meio para chegar a um resultado, e outros que acreditam que a etnografia não é apenas o meio para algo, e sim o próprio fim. Levando em conta que esta discussão também não pode ser tão reducionista, afinal, existem muitos modos de fazer etnografia, e nesta coletânea pensada pelo ponto de vista de dois historiadores, vemos a etnografia entendida principalmente como uma forma de contar uma história, ou de entender uma situação.

\footnotetext{
${ }^{1}$ Mestranda em Ciências Sociais pelo Programa de Pós-Graduação em Ciências Sociais da EFLCH-Unifesp. Contato: marianna.cbandrade@gmail.com
} 
Logo na introdução do livro, Hollanda conta um pouco o motivo pelo qual a coletânea havia sido escrita. A decisão se deu logo após uma constatação: a existência de um número expressivo de estudos acadêmicos dedicados à essa torcida organizada em questão. Segundo o autor, os artigos focados no grêmio Gaviões da Fiel acumulam-se desde pelo menos o final dos anos 1970, alguns anos após a fundação da torcida que se deu no ano de 1969.

A primeira parte do livro foi intitulada de "Ensaios" e conta com sete textos de diversos autores que originalmente já haviam sido publicados em revistas, livros ou dissertações e que foram replicadas na coletânea com devidas autorizações. Estes ensaios abordam de maneira geral a história de fundação dos Gaviões da Fiel, como também fatos históricos que fizeram parte do Corinthians como um todo, como é o caso do texto do antropólogo José Paulo Florenzano que conta a relação dos Gaviões da Fiel com a Democracia Corinthiana, ou até mesmo o texto de um dos organizadores da coletânea, Plínio Negreiros, que fala sobre a torcida corinthiana de modo geral em um momento histórico que ficou conhecido como ocupação do Maracanã em 1976, para a final de um campeonato brasileiro. Além disso, após o mapeamento por parte dos organizadores das produções existentes sobre a temática, alguns especialistas foram convidados a produzir capítulos inéditos para a coletânea. Desse modo, existem textos mais históricos dos anos 1970 e 1980, na mesma proporção que há capítulos mais contemporâneos sobre a situação da torcida na atualidade. Situado na Parte II do livro, os "Relatos Etnográficos" contam com a participação de diversos estudiosos na temática e apresentam etnografias tanto em caravanas e jogos, ou na quadra sede dos Gaviões da Fiel, quanto na presença da agremiação no carnaval paulistano, resultando então em quatro tipos de relatos etnográficos que serão detalhados mais adiante nesta resenha. Para finalizar, a terceira parte do livro é intitulada de "Cronologia" e contém dois capítulos finais referentes a uma construção textual mais cronológica que buscou fornecer o máximo de informações objetivas acerca de fatos históricos da torcida corinthiana, de personalidades e eventos ligados à história e memória dos Gaviões.

Como dito anteriormente, esta resenha buscará se apoiar sobretudo na parte dos relatos etnográficos da coletânea, com o objetivo de analisar as diversas possibilidades do fazer etnográfico em diferentes lugares, sob um único objeto de estudo. 
O primeiro relato etnográfico é intitulado de "Os gaviões da fiel e a águia do capitalismo" e constitui a transcrição da parte etnográfica da dissertação de mestrado de Benedito Tadeu César, defendida em junho de 1981 no Programa de Pós-Graduação em Antropologia Social da Universidade Estadual de Campinas (Unicamp). Benedito era professor no departamento de ciências sociais na Universidade Federal do Espírito Santo quando veio para São Paulo fazer etnografia sobre os Gaviões da Fiel, de modo muito descritivo o autor conta suas dificuldades na entrada do campo, não só pela complexidade que existe neste momento, mas também pela condição de estar em uma cidade desconhecida por ele. A ideia do autor era de acompanhar jogos finais do Campeonato Brasileiro diretamente das arquibancadas, do lado dos Gaviões.

Futebolisticamente falando, esse era um momento muito oportuno, pois o Corinthians estava próximo de ser campeão depois de muitos anos sem título. Entretanto, para assistir aos jogos nas arquibancadas destinadas às torcidas organizadas do Corinthians, especificamente aos Gaviões, Benedito precisou se filiar à agremiação e conseguir imediatamente uma camiseta dos gaviões para que pudesse ir ao jogo, tudo isso somado ao fato de ser uma pessoa completamente estranha, de fora da cidade e que, na verdade, nem torcida para o Corinthians. As primeiras linhas do relato etnográfico de Benedito contam justamente essas negociações iniciais que ocorreram na quadra-sede dos Gaviões da Fiel, no dia do primeiro jogo que Benedito pretendia assistir. Em todos os momentos de sua escrita, vemos que o autor se preocupava em ser um deles. Para Benedito, só seria possível a observação participante caso ele fosse filiado à torcida. Era preciso ser um "gavião" para ser aceito e visto como um. E foi desse modo, apenas após se associar à torcida, que conseguiu iniciar conversas na quadra antes da ida ao estádio. Entretanto, o autor relata que as dificuldades obviamente permaneceram, pois durante as conversas os gaviões percebiam que Benedito não compartilhava das memórias torcedoras que eles compartilhavam. Afinal, o autor notou, então, que não era necessário ser somente um "gavião", vestir a camiseta e ter uma carteirinha, a identidade torcedora se constituía principalmente pelas memórias partilhadas em conjunto ao longo dos anos.

Além disso, Benedito relata que em suas primeiras conversas foi preciso esconder o gravador para que os "gaviões" falassem as coisas com mais naturalidade, pois a figura do antropólogo realizando uma etnografia, para muitos não era entendida exatamente dessa forma. Benedito conta que a imagem de uma pessoa estranha com um gravador na mão no 
meio da sede da torcida soava como algo jornalístico, o que fazia com que as pessoas se comportassem de forma não espontânea e, ao mesmo tempo, empolgadas com a ideia de "estar virando notícia". Apesar dos relatos serem ricos em detalhes, como a primeira ida dele ao estádio junto com diversos membros da torcida, a chegada ao estádio, os cantos, a rivalidade e xingamentos em direção à torcida adversária, estas questões todas foram poucos exploradas num sentido mais antropológico, pensando que tais questões usualmente são muito exploradas em estudos acadêmicos que combinam antropologia, futebol e torcidas. Possivelmente isso seja decorrente do fato de que este relato etnográfico é a transcrição da parte empírica de sua dissertação, e a parte teórica não tenha sido incluída aos relatos. Sentese, portanto, certa ausência de um maior diálogo entre "teoria" e "empiria".

No total, os relatos etnográficos contaram com algumas visitas a sede dos Gaviões, incluindo em uma delas a famosa reunião para novos sócios da agremiação, que constitui basicamente na apresentação dos valores da torcida, e esclarecimento de possíveis dúvidas para os novos torcedores, tal parte também foi pouco explorada textualmente pelo Benedito. Além disso, a pesquisa de campo foi feita em 4 jogos no estádio do Morumbi com os "gaviões". Devido à época do ano em que a pesquisa de campo foi feita, em algumas de suas idas à sede dos Gaviões da Fiel, Benedito também presenciou a preparação para o carnaval e a relação eufórica da combinação samba-futebol entre os associados. Entretanto, mesmo sendo uma temática complexa e que suscita diversas discussões, não foi algo que teve muita ênfase em seus registros, diferente do segundo relato etnográfico que falaremos a seguir.

Intitulado de "Uma torcida que samba: o Grêmio Recreativo Gaviões da Fiel” é o segundo relato etnográfico da coletânea, escrito por Arthur Bueno, resultado de uma pesquisa de campo feita por alguns meses com os Gaviões da Fiel. O texto original foi apresentado no II Seminário de Antropologia Urbana da Universidade de São Paulo, organizado pelo Núcleo de Antropologia Urbana (NAU).

A proposta deste relato etnográfico consistiu em comparar dois universos sociais: o samba e o futebol; atentando para o que os distingue e aproxima. Levando em consideração principalmente a ideia complexa de uma torcida organizada de futebol que adentra um universo completamente novo, tornando-se também uma escola de samba, ou, como muitos componentes da agremiação costumam dizer, uma torcida que samba. 
Os procedimentos metodológicos deste relato se diferem do primeiro. Pois neste, inicialmente foi feita uma pesquisa de campo na internet, com consultas aos sites de agremiações carnavalescas e de torcidas organizadas. Posteriormente, foi realizada uma pesquisa de campo com observação direta e entrevistas no Grêmio Gaviões da Fiel. Além das pesquisas de campo na internet e na quadra dos Gaviões, foi realizado um levantamento bibliográfico como o objetivo de reconstruir a história do futebol e do carnaval na cidade de São Paulo. Arthur inicia seu relato discutindo essa bibliografia.

O autor lança mão de autores que estudam a temática do futebol sob uma ótica urbana, como Luiz Henrique Toledo, para contar o surgimento do futebol e as formas de sua sociabilidade na cidade de São Paulo. Paralelo a isso, também remonta a história do samba e do carnaval na cidade, pois, para ele, carnaval e futebol são capazes de explicar duas formas distintas de organização do lazer acompanhada do processo de urbanização.

Logo após introduzir teórica e historicamente estes pontos, Arthur parte para os relatos etnográficos de suas experiências entre os Gaviões. A começar pelo ambiente da quadra da instituição, localizada no bairro do Bom Retiro, descrito como um espaço que é apropriado e ressignificado de várias maneiras, servindo de base para diversos tipos de sociabilidade, desde feijoadas com samba, até comemorações de títulos de campeonatos. O autor explora também diversos processos de identificação entre os integrantes da torcida, abordando como eles se reconhecem como uma "família". Os relatos etnográficos são intercalados ora por descrições de determinadas situações feitas pelo próprio autor, ora por mensagens dos próprios gaviões copiadas do site da torcida, onde foi feita a etnografia virtual.

$\mathrm{O}$ autor explora alguns elementos fundamentais da sociabilidade interna da agremiação torcedora e carnavalesca, bem como a rivalidade entre torcidas que só podem existir no âmbito do futebol, e não do carnaval. Como o exemplo da relação que existe entre as escolas de samba Mancha Verde e Gaviões da Fiel, que só se constitui no período do carnaval, e que é inconcebível em outros momentos do ano. Observa também a questão da virilidade e da masculinidade que é muito exaltada nos Gaviões enquanto torcida organizada, mas que na ala do carnaval, esse aspecto desapareceria, com a maior presença feminina e de homossexuais. Para fazer análise destes pontos levantados, o autor lança mão principalmente do conceito de habitus de Pierre Bourdieu. Conclui então que a relação destes dois universos sociais tão diferentes dentro de uma mesma instituição permite 
diversos cruzamentos de lógicas simbólicas, que gera contradições e diferentes opiniões nada consensuais no universo da torcida.

O terceiro relato etnográfico é intitulado de "Relato de campo: uma visita a sede dos Gaviões no bairro do Bom Retiro" e faz parte do acervo do Centro de Referência do Futebol Brasileiro, uma área do Museu do Futebol que consolida todas as informações já pesquisadas pelo museu. Este texto em questão e a pesquisa que lhe deu origem foram produzidos por uma equipe de pesquisadores que obteve inclusive apoio financeiro da FINEP e do CNPq para tal.

Este relato se apresenta de forma mais breve que os outros, pois a observação participante foi feita apenas em 4 dias. De forma bastante descritiva, os pesquisadores descrevem como é a quadra sede dos Gaviões da Fiel, apontando a localização de cada coisa dentro daquele espaço, como a sala dos patrimônios e troféus, sala das bandeiras, etc. Durante o primeiro dia de campo, os pesquisadores conheceram e conversaram também com algumas pessoas que exerciam funções dentro da torcida, dentre eles: Donizete, presidente dos Gaviões da Fiel; o vice-presidente da torcida, conhecido como B.O; e Pulguinha, também participante da direção da torcida e da Confederação Nacional das Torcidas Organizadas (CONATORG). A conversa entre estes membros e os pesquisadores foi principalmente ligada a temas em relação a hierarquia interna da torcida e o funcionamento das chapas administrativas, assembleias, etc.

A outra visita a quadra dos Gaviões ocorreu em um sábado, dia de reunião de apresentação de novos sócios. Os pesquisadores descrevem a reunião em si como um rito de passagem ou de iniciação para quem chega na agremiação. Ali são apresentadas principalmente a história e memória dos Gaviões, principal fator que deve ser conhecido por quem está chegando. Atentos a todas as dúvidas e perguntas que iam surgindo em cada parte da reunião, os pesquisadores apresentam detalhes da dinâmica e dos acontecimentos da reunião em seus relatos.

A última visita feita à sede dos Gaviões por essa equipe de pesquisa foi em um domingo, em dia de clássico entre Corinthians e Santos pela 24 a rodada do Campeonato Brasileiro. A ideia inicial era de que os torcedores se encontrassem na quadra, e seguissem juntos até o Estádio do Pacaembu, onde aconteceria a partida. Os pesquisadores narram todos os rituais que sucedem a ida ao estádio, a chegada, os cantos, gritos e bandeiras, e assistiram à partida com os dirigentes da torcida. 
O quarto e último relato etnográfico que consta na coletânea é intitulado de "Viajando com os Gaviões: narrativas de uma caravana do Movimento Rua São Jorge", escrito por Vitor Canale e é na verdade um curto relato sobre uma etnografia feita em uma caravana com o Movimento da Rua São Jorge. Antes de descrever em detalhes a experiência etnográfica em questão, o autor retrocedeu historicamente contando um pouco sobre o surgimento do Grêmio Gaviões da Fiel, narrando alguns "rachas" ou dissidências que sua história acumula, pois, para ele, olhar os Gaviões como um quadro associativo homogêneo não nos deixaria analisar as contradições, inflexões e dramas existentes em sua história. $\mathrm{O}$ autor conta, então, da briga interna entre os Gaviões que resultou na criação da segunda maior torcida organizada do Corinthians, a Camisa 12, chegando até a criação do Movimento da Rua São Jorge, que foi seu objeto etnográfico.

O Movimento Rua São Jorge surge em 2007 e se mantém até o ano de 2012 (ano em que foi feita a etnografia), sua criação é justificada por um descontentamento de setores da torcida, incluindo várias lideranças. Os torcedores que faziam parte desse movimento viam o aumento da influência do carnaval com um processo de ampliação da mercadorização da torcida e da sua divisão em diversos interesses. Conforme essa perspectiva, isso poderia culminar em um enfraquecimento da arquibancada por causa de demandas secundárias e da incapacidade de promover críticas ao Corinthians se necessário, já que se estabeleceria uma relação de clientelismo com o clube. Aqui o autor não explica de maneira mais detalhada no que consistiria a relação de clientelismo entre a torcida, o carnaval e o próprio clube. Entretanto, ressalta que o interesse do Movimento da Rua São Jorge não era de formar outra torcida organizada, segundo o autor o "exílio" do movimento tinha por objetivo protestar e transformar os Gaviões da fiel, para voltar em uma nova conjuntura, na qual o futebol fosse novamente o principal centro das atenções e a torcida pudesse ser novamente guiada pela ideologia fundadora dos Gaviões, "Lealdade, Humildade e Procedimento".

E foi nesse contexto que o autor fez sua etnografia com o movimento, em uma caravana para o Rio de Janeiro a fim de assistir a uma partida entre Flamengo e Corinthians, válida pelo Campeonato Brasileiro. A inserção foi proporcionada por seu informante que era uma das lideranças do movimento. Em seu relato, Vitor conta sobre a concentração na sede do movimento, que se localizava em um outro lugar longe da sede dos Gaviões da Fiel. Ele relata a saída dos ônibus e como se dava a distribuição de pessoas em cada ônibus 
através das regiões de São Paulo. Por exemplo, as divisões entre os ônibus da zona norte e ônibus da zona leste, ou entre aqueles que levava as pessoas mais ou menos briguentas, entre outras razões para segmentar a torcida; o autor relata ainda as tensões em cada parada na estrada e o comportamento sempre criminalizante da polícia com as torcidas organizadas, até a chegada à cidade do Rio de Janeiro, apontando as rivalidades e as brigas já pré-estabelecidas com a torcida adversária etc. Nesse capítulo, há um tema também explorado nos demais relatos etnográficos, que é o da virilidade e masculinidade na sociabilidade destes torcedores, que, de certa forma, marca a sociabilidade que é característica desta torcida organizada. Logo após esse relato ter sido feito, o Movimento da Rua São Jorge se desmanchou por questões não exploradas pelo autor, e se juntou novamente aos Gaviões da Fiel.

E é com este relato etnográfico que esta seção do livro é finalizada, dando início a última e mais curta seção do livro que é intitulada "Cronologia", esta seção conta com apenas dois capítulos, o primeiro remonta à história de fundação dos Gaviões, ano a ano desde sua fundação, passando pelos acontecimentos históricos mais marcantes da torcida. Já o último capítulo traça uma linha do tempo, indo um pouco mais além, a partir de 1910, ano de fundação do Sport Club Corinthians Paulista, separando os acontecimentos mais importantes do clube, década por década, chegando até a década de 2010, momento em que a coletânea foi escrita.

Como dito no início, essa resenha buscou justamente discutir a dimensão etnográfica desta coletânea sobre os Gaviões da Fiel. Os historiadores que organizaram o livro conseguem combinar memória e cotidiano nessas três partes do livro, fazendo com que o leitor adentre o universo complexo de uma torcida organizada de futebol.

No que diz respeito à parte dos relatos etnográficos que foi o foco desta resenha, podemos concluir que existem inúmeras formas de fazer etnografia e estar em campo. Alguns relatos etnográficos da coletânea nos mostram as controvérsias que a etnografia pode nos trazer, principalmente nos relatos mais longos em que os pesquisadores estiveram mais tempo em campo nos mostraram a possibilidade do pesquisador ser afetado em campo, o que permite que ele viva as experiências com seus interlocutores e não apenas escreva sobre eles. Isso aparece principalmente nos relatos em que os pesquisadores vivenciaram experiências como: caravanas, ida a jogos importantes junto com a torcida etc. 
Em contrapartida, os relatos mais curtos, limitados pelo tempo obtido para fazer a pesquisa de campo, aparecem muito mais como um método de coleta de dados do que como um relato etnográfico mais completo. A etnografia nunca pode ser vista apenas como um método de coleta de informações ou uma forma de apenas descrever situações, porém, se feita em poucos dias, pode ser reduzida apenas a isto e é esta sensação que os relatos mais curtos desta coletânea nos deixaram.

Por fim, sabendo da infinidade da etnografia como uma experiência que nunca acaba de fato e que está sempre por fazer, a coletânea abre um campo de possibilidades a partir dos relatos já coletados para novas pesquisas na temática de torcidas organizadas, especialmente os Gaviões da Fiel. 